\title{
Association of Pro-apoptotic Bad Gene Expression Changes with Benign Thyroid Nodules
}

\author{
NURDAN GÜL ${ }^{1}$, BERNA TEMEL ${ }^{1}$, DURAN USTEK ${ }^{2}$, SEMA SIRMA-EKMEKÇI ${ }^{2}$, YERSU KAPRAN ${ }^{3}$, \\ FATIH TUNCA ${ }^{4}$, YASEMIN GILES-ŞENYÜREK ${ }^{4}$, UĞUR ÖZBEK ${ }^{2}$ and FARUK ALAGÖL ${ }^{1}$ \\ ${ }^{1}$ Division of Endocrinology and Metabolism, Department of Internal Medicine, ${ }^{3}$ Department of Pathology and \\ ${ }^{4}$ Department of Surgery, Istanbul Faculty of Medicine, Istanbul University, Istanbul, Turkey; \\ ${ }^{2}$ Department of Genetics, Institute for Experimental Medical Research, Istanbul University, Istanbul, Turkey
}

\begin{abstract}
Background/Aim: This study aimed to investigate the role of the mitochondrial apoptotic pathway in benign thyroid nodules. Materials and Methods: Paired samples of nodular and normal tissues were collected from 26 patients with nodular goiters undergoing thyroidectomy. Variable expression of Bcl-2, Bax and Bad genes were evaluated by quantitative PCR. Results: Expression level of Bad gene in nodules was found to be significantly decreased compared to normal tissues $(p=0.049)$. A positive correlation was observed between nodule size and Bad expression levels (correlation coefficient $=0.563, \quad p=0.004) ; \quad$ and this correlation was stronger in hot nodules $(n=18$, correlation coefficient $=0.689, p=0.003)$. No significant difference was observed between nodular and normal tissue expressions of Bax and Bcl-2. Conclusion: These results suggest that Bad expression correlates with the size of benign thyroid nodules and also its relatively lower expression in nodules, warrant further investigation.
\end{abstract}

The etiology of benign thyroid nodules is generally believed to be multifactorial in origin. Environmental factors like iodine deficiency, genetic predisposition and endogenous factors including gender may contribute to nodule development (1). A monoclonal origin detected in the

This article is freely accessible online.

This study was supported by Istanbul University Research Fund (T-285/18062003).

Correspondence to: Dr. Nurdan Gül, Istanbul Faculty of Medicine, Department of Internal Medicine, Division of Endocrinology and Metabolism, 34093 Fatih, Istanbul, Turkey. Tel: +90 2124142000/ 32735, Fax: +90 2125232891, e-mail: nurdan.gul@instanbul.edu.tr

Key Words: Benign thyroid nodules, apoptosis, Bad, Bcl-2, Bax, gene expression. majority of thyroid nodules implicates a benign nodular development from a single mutated thyroid cell. Activating thyrotropin receptor and alpha subunit of the $\mathrm{G}$ protein $\left(\mathrm{Gs}_{\alpha}\right)$ mutations are prevalent in autonomously functioning thyroid nodules (AFTNs), but knowledge concerning the molecular etiology of benign cold thyroid nodules is limited (2-5).

In normal tissues, total cell mass is maintained by the dynamic balance between cell proliferation and programmed cell death, apoptosis. Several control systems maintain homeostasis by both stimulating and inhibiting apoptosis (6). Death receptors (DRs), which are proteins related to the TNF receptors (TNFRs), also contribute to the maintenance of homeostasis by modulating the apoptotic threshold of the cell in response to a variety of chemical substances (7).

The apoptotic machinery of the cell apart from the DRs includes adaptor molecules, caspases and the proteins of the Bcl-2 family. Bcl-2 family includes both pro-survival and pro-apoptotic members (7). Its pro-survival members (Bcl-2, Bcl-xL, Bcl-w, Mcl-1 and A1) oppose two proapoptotic groups, known as the Bax group and the $\mathrm{BH}$ only proteins. Members of the Bax group (Bax, Bak and Bok) are structurally similar to Bcl-2 and bear three ' $\mathrm{BH}$ ' (Bcl-2 homology) domains, whereas the $\mathrm{BH}$-only proteins, which include Bim, Bad, Bid, Bik, Bmf, Puma, Noxa and Hrk, share only the BH3 interaction domain (8).

Apoptosis provides protection from the possible consequences of increased or uncontrolled cell proliferation, which could lead to hyperplasia or neoplasia (9). Fas and TNF-related apoptosis inducing ligand (TRAIL) dependent apoptotic pathways are the two most frequently investigated pro-apoptotic pathways with relevance to thyroid homeostasis (10-12). Recent evidence has emphasized on the importance of apoptosis in the pathogenesis of thyroid cancer and autoimmune thyroid disorders (13), and cell cycle modulators controlled by the Bcl-2 family proteins were shown to be important in the pathogenesis of thyroid follicular neoplasms (14). However, the role of apoptosis in 
the molecular pathogenesis of benign thyroid nodules has not been extensively investigated. More subtle impairments of growth inhibition compared to those observed in malignant conditions may participate in the imbalanced tissue homeostasis that results in nodular goiter; and thyroid cells with advantageous mutations can further proliferate and develop into benign thyroid nodules.

The purpose of this pilot study was to investigate the role of Bcl-2 apoptotic pathway in the pathogenesis of benign thyroid nodules by measuring mRNA levels of pro-survival $\mathrm{Bcl}-2$ and pro-apoptotic Bax and Bad genes in paired samples of nodular and normal (non-nodular) appearing thyroid tissues.

\section{Materials and Methods}

Patients and tissues. The local ethics committee approved the protocol of this study, and a written informed consent was obtained from all participants. Thyroid tissue samples were collected from 52 patients with solitary or multinodular goiters undergoing surgery for the removal of thyroid nodules. All patients were negative for anti-thyroglobulin and anti-thyroperoxidase antibodies. Specimens collected from dominant nodules and apparently normal nonnodular thyroid tissues from each patient were snap-frozen in liquid nitrogen before RNA isolation. During histopathologic examination, 26 of 52 patients were excluded from the study either due to thyroid cancer or due to lymphocytic infiltration. Paired samples of the nodular and normal tissues of the remaining 26 patients comprised the study group. The nodules were classified as cold or hot based on their scintigrafic features. Nodule sizes were measured by both preoperative ultrasound and postoperative macroscopic examination, and the results of the latter were recorded.

Quantitative RT-PCR. Total RNA was extracted from the samples using the RNeasy Fibrous Tissue Kit (Qiagen, Hilden, Germany) according to the manufacturer's instructions. One microgram of total RNA was reverse transcribed in a $20-\mu$ l reaction volume containing $5 \mu \mathrm{g} / \mathrm{ml}$ random hexamers, $0,5 \mathrm{mM}$ dNTP, 0,01 M DTT, $1 \mathrm{U} / \mu \mathrm{l}$ ribonuclease inhibitor, $2.5 \mathrm{U} / \mu \mathrm{l}$ reverse transcriptase (all enzymes and chemicals were supplied from MBI Fermantas, Germany). The PCR conditions for the cDNA were as follows: 10 min at $70^{\circ} \mathrm{C}, 1 \mathrm{~h}$ at $37^{\circ} \mathrm{C}$ and $5 \mathrm{~min}$ at $99^{\circ} \mathrm{C}$ and was stored at $-20^{\circ} \mathrm{C}$ prior to quantitative PCR analysis.

Expression levels of the Bcl-2, Bax and Bad genes were analyzed by quantitative PCR using LightCycler (Roche Diagnostics GmbH, Germany). We have used the SYBR Green 1 dye (Roche, Mannheim, Germany) binding method. Oligonucleotide primers for the genes analyzed and for $\beta 2$-microglobulin (B2M) as endogenous control were as follows: $\mathrm{Bcl}-2$ - forward 5'-AGG AAG TGA ACA TTT CGG TGA C-3' and Bcl-2 - reverse 5'-GCT CAG TTC CAG GAC CAG GC-3', Bax - forward 5'-GAT GAT CCA TGT TTT CAG CGA C-3' and Bax - reverse 5'-CTC CAC AAA CCC ATC CCA G3', Bad - forward 5'- GAG TGA GCA GGA AGA CTC CAG C3' and Bad - reverse 5'-TCC ACA AAC TCG TCA CTC ATC C-3', B2M - forward 5' -TGC CGT GTG AAC CAT GTG AC-3' and B2M - reverse: 5'-ACC TCC ATG ATG CTG CTT ACA-3'.

The following amplification program was used: One min at $95^{\circ} \mathrm{C}$, followed by 40 cycles consisting of $10 \mathrm{sec}$ at $95^{\circ} \mathrm{C}, 5 \mathrm{sec}$ at $58^{\circ} \mathrm{C}$, and $20 \mathrm{sec}$ at $72^{\circ} \mathrm{C}$. Melting curve analysis consisted of $0 \mathrm{sec}$ at $95^{\circ} \mathrm{C}, 10 \mathrm{sec}$ at $65^{\circ} \mathrm{C}$, and $10 \mathrm{sec}$ at $95^{\circ} \mathrm{C}$. Standard curves were generated for each amplification using serial dilutions of a cDNA mixture expressing B2M. Expression of each gene was calculated with a program found in LightCycler software. Relative expression units (REUs) were calculated using expression of the B2M gene as endogenous control.

Statistical analysis. Results are expressed as the mean $\pm \mathrm{SD}$, median (minimum-maximum). Expression levels were compared using nonparametric Wilcoxon signed-rank test. Correlation of Bcl-2, Bax and Bad gene expression with clinical parameters was analyzed using Spearman test and $p<0.05$ was considered statistically significant.

\section{Results}

We analyzed normal and nodular thyroid tissues of 26 patients to investigate the role of $\mathrm{Bcl}-2$ mitochondrial apoptotic pathway in the pathogenesis of benign thyroid nodules, and 18 of the nodules were classified as hot and 8 as cold. Table I summarizes the characteristics of each patient included in the study.

Relative mRNA expression levels of the studied Bcl-2, Bax and Bad genes are given in Table II. Analysis of the entire set of benign nodules $(n=26)$ revealed that Bad mRNA expression levels were significantly lower than those in apparently normal thyroid tissues from the same patients $(p=0.049)$. There was no significant difference observed in the levels of Bax and Bcl-2 mRNA expressions between the paired nodular and normal tissues.

In the subgroup analysis of patients with hot $(n=18)$ or cold $(n=8)$ nodules, no significant differences were observed in the expression levels of Bcl-2, Bax and Bad genes between the normal and nodular thyroid tissues.

A strong positive correlation was observed between nodule size and Bad mRNA expression levels of the entire set of nodules (correlation coefficient $=0.563, p=0.004$ ). This correlation was stronger when only hot nodules were considered (correlation coefficient $0.689, p=0.003$ ).

\section{Discussion}

In this pilot study, we observed decreased mRNA expression of pro-apoptotic Bad gene in the nodules compared to the paired normal thyroid tissues from the same patients despite the positive correlation between the size of the nodule and the amount of Bad mRNA.

A sensitive quantitative RT-PCR method was selected to detect subtle changes, which can be associated with a benign nodule development. We expected that these expression changes would not be prominent enough to be detected like those changes observed when malignant thyroid nodules were compared with benign nodules (14). In agreement with a previous study using immunohistochemical methods, no significant difference was observed in the expression levels of Bcl-2 and Bax genes between the normal and benign 
Table I. Clinical and histological characteristics of the study group.

\begin{tabular}{|c|c|c|c|c|c|c|c|c|}
\hline No & $\begin{array}{l}\text { Age } \\
\text { (years) }\end{array}$ & Gender & $\begin{array}{l}\text { TSH value before } \\
\text { surgery }(\mathrm{mIU} / \mathrm{l})\end{array}$ & $\begin{array}{c}\text { Nodule } \\
\text { diameter }(\mathrm{mm})\end{array}$ & Scintigraphy & Diagnosis & $\begin{array}{c}\text { Treatment before } \\
\text { surgery }\end{array}$ & Histopathology \\
\hline 1 & 73 & $\mathrm{~F}$ & 0.571 & 51 & Cold & MNG & None & AN \\
\hline 2 & 74 & F & 0.697 & 45 & Cold & MNG & None & AN \\
\hline 3 & 70 & $\mathrm{~F}$ & 2.66 & 34 & Cold & MNG & None & FA \\
\hline 4 & 41 & $\mathrm{~F}$ & 1.82 & 23 & Cold & MNG & None & AN \\
\hline 5 & 54 & M & 1.15 & 38 & Cold & SN & None & FA \\
\hline 6 & 59 & $\mathrm{~F}$ & 2.20 & 12 & Cold & MNG & None & AN \\
\hline 7 & 38 & M & 0.277 & 40 & Cold & MNG & None & AN \\
\hline 8 & 19 & $\mathrm{~F}$ & 0.686 & 20 & Cold & SN & None & AN \\
\hline 9 & 53 & $\mathrm{~F}$ & 0.005 & 45 & Hot & TMNG & PTU & AN \\
\hline 10 & 48 & M & 0.007 & 23 & Hot & TMNG & MMI & AN \\
\hline 11 & 36 & M & 0.462 & 47 & Hot & SN & None & AN \\
\hline 12 & 54 & $\mathrm{~F}$ & 0.071 & 38 & Hot & TMNG & PTU & $\mathrm{AN}$ \\
\hline 13 & 53 & M & 0.023 & 49 & Hot & $\mathrm{TA}$ & None & AN \\
\hline 14 & 52 & $\mathrm{~F}$ & 0.149 & 28 & Hot & TMNG & None & AN \\
\hline 15 & 53 & F & 0.018 & 28 & Hot & $\mathrm{TA}$ & None & AN \\
\hline 16 & 57 & M & 0.006 & 45 & Hot & TMNG & MMI & AN \\
\hline 17 & 60 & M & 0.022 & 33 & Hot & TMNG & MMI & AN \\
\hline 18 & 50 & M & 0.248 & 43 & Hot & TMNG & MMI & AN \\
\hline 19 & 40 & M & 0.499 & 30 & Hot & MNG & None & AN \\
\hline 20 & 57 & $\mathrm{~F}$ & 0.054 & 25 & Hot & TMNG & None & AN \\
\hline 21 & 72 & $\mathrm{~F}$ & 0.008 & 27 & Hot & TMNG & PTU & AN \\
\hline 22 & 56 & $\mathrm{~F}$ & 0.013 & 45 & Hot & TMNG & MMI & AN \\
\hline 23 & 39 & M & 0.44 & 14 & Hot & MNG & None & AN \\
\hline 24 & 51 & M & 0.019 & 35 & Hot & TMNG & MMI & AN \\
\hline 25 & 57 & $\mathrm{~F}$ & 0.186 & 25 & Hot & TMNG & MMI & AN \\
\hline 26 & 52 & $\mathrm{~F}$ & 0.153 & 32 & Hot & TMNG & None & AN \\
\hline
\end{tabular}

M: Male; F: female; MNG: multinodular goiter; SN: solitary nodule; TMNG: toxic multinodular goiter; TA: toxic adenoma; PTU: propylthiouracil; MMI: methimazole; AN: adenomatous goiter; FA: follicular adenoma.

nodular thyroid tissues (15). However, the observation of a positive correlation between the level of Bad gene expression and nodule size as well as a relative decrease in its expression may suggest that Bad may have a regulatory role in the development of benign thyroid nodules and an imbalance in its expression may contribute to the pathogenesis of nodule development.

Bad (Bcl-2 antagonist of cell death, Bcl-2 binding component 6) is a small pro-apoptotic protein consisting of 168 amino acids (16). It plays an important role in connecting growth signaling pathway to cell death pathway. Bad deficient mice are developmentally normal by most criteria, however, isolated thymocytes, fibroblasts, and epithelial cells from Bad deficient mice were found to be resistant to cell death induced by growth factor withdrawal, consistent with a pro-death function of Bad under these conditions. Furthermore, Bad deficient mice develop B cell lymphomas and other malignancies, and this propensity is dramatically increased by exposure to limited $\gamma$-irradiation. The apoptotic activity of $\mathrm{Bad}$ is inhibited by phosphorylation (17).
Table II. Expression of Bcl-2 family apoptotic genes in thyroid tissues $(n=26)$.

\begin{tabular}{llc}
\hline Gene & Tissue & $\begin{array}{c}\text { Relative Expression Unit } \\
\text { Mean } \pm \text { SD (median (minimum-maximum) })\end{array}$ \\
\hline Bcl-2 & Normal & $0.333 \pm 0.437(0.116(0.006-1.541))$ \\
& Nodule & $0.345 \pm 0.643(0.115(0.021-3.002))$ \\
Bax & Normal & $0.042 \pm 0.029(0.035(0.005-0.117))$ \\
& Nodule & $0.066 \pm 0.077(0.035(0.0002-0.328))$ \\
Bad & Normal & $0.048 \pm 0.097(0.020(0.003-0.485))$ \\
& Nodule & $0.017 \pm 0.012(0.014(0.003-0.057))$ \\
\hline
\end{tabular}

Mezosi and colleagues examined TRAIL and FasL- induced apoptotic pathways in primary thyroid cells from 17 patients with nodular goiter, using 10 normal thyroids as controls (18). 
Although normal thyroid cells could be sensitized in vitro to TRAIL and FasL by inflammatory cytokines, the majority of goiter samples showed resistance to death ligands after cytokine pretreatment. The resistance of goiter cells to TRAIL was not caused by the altered surface expression of death receptors or the overexpression of well-known intracellular inhibitors such as cFLIP, Bcl-2, or inhibitor of apoptosis proteins raising the possibility that other inhibitors or a downregulation of pro-apoptotic proteins might be responsible. In a subset of goiters they found increased proteasome activity, and they suggested that this increase might be responsible for the down regulation of pro-apoptotic proteins as most intracellular proteins are degraded by the proteasome complex (18). At another study of AFTNs using microarray technology, Wattel and colleagues showed overexpression of anti-apoptotic genes and under-expression of pro-apoptotic genes compatible with their low apoptosis rate (19).

Recent studies suggest a role for the phosphoinositide 3kinase (PI3K)/Akt and Bad gene pathway in the development of papillary thyroid cancer $(20,21)$, which can be a supportive finding for the critical role of Bad in the survival of thyroid cells and nodulogenesis. The correlation of $\mathrm{Bad}$ gene mRNA expression with nodule size further supports its importance as a regulatory protein in thyroid cell apoptosis, however its expression may not be sufficient enough to inhibit the development of nodules in some patients with genetic or epigenetic alterations leading to an imbalance with relatively lower Bad gene expression.

This pilot study has several limitations, mainly due to lack of confirmatory findings using additional methods to document the expression changes. As expected, the observed changes in the expression of the Bad gene were not so strong enough to be documented by immunohistochemical methods in benign nodules, and the findings of this study are promising enough to be studied in larger groups with additional sensitive tools to detect minimal changes in gene expression.

\section{Conclusion}

The positive correlation of Bad expression with nodule size and a relative decrease in the mRNA expression level of Bad in benign thyroid nodules suggest that Bad may be an important regulator of thyroid cell apoptosis. These preliminary findings may indicate a role for deregulated Bad gene expression in the pathogenesis of thyroid nodules and warrant further investigations in larger series of patients and experimental models.

\section{Conflicts of Interest}

The Authors declare that they have no conflicts of interest relevant to this study. No financial support other than Istanbul University Research Fund (T-285/18062003) was received.

\section{Acknowledgements}

The Authors thank their colleague Professor Ahmet Gül for valuable discussions and statistical analysis. This study was supported by Istanbul University Research Fund (T-285/18062003).

\section{References}

1 Hegedüs L, Bonnema SJ and Bennedbaek FN: Management of simple nodular goiter: current status and future perspectives. Endocr Rev 24: 102-132, 2003.

2 Krohn K, Führer D, Bayer Y, Eszlinger M, Brauer V, Neumann $\mathrm{S}$ and Paschke R: Molecular pathogenesis of euthyroid and toxic multinodular goiter. Endocr Rev 26: 504-524, 2005.

3 Parma J, Duprez L, Van Sande J, Hermans J, Rocmans P, Van Vliet G, Costagliola S, Rodien P, Dumont JE and Vassart G: Diversity and prevalence of somatic mutations in the thyrotropin receptor and Gs alpha genes as a cause of toxic thyroid adenomas. J Clin Endocrinol Metab 82: 2695-2701, 1997.

4 Trülzsch B, Krohn K, Wonerow P, Chey S, Holzapfel HP, Ackermann F, Führer D and Paschke R: Detection of thyroidstimulating hormone receptor and Gs $\alpha$ mutations: in 75 toxic thyroid nodules by denaturing gradient gel electrophoresis. J Mol Med (Berl) 78: 684-691, 2001.

5 Ferraz C, Lorenz S, Wojtas B, Bornstein SR, Paschke R and Eszlinger M: Inverse correlation of miRNA and cell cycleassociated genes suggests influence of miRNA on benign thyroid nodule tumorigenesis. J Clin Endocrinol Metab 98: E8-16, 2013.

6 Lumachi F and Basso S: Apoptosis: life through planned cellular death regulating mechanisms, control systems, and relations with thyroid diseases. Thyroid 12: 27-34, 2002.

7 Sarlis NJ and Gourgiotis L: Molecular elements of apoptosisregulating pathways in follicular thyroid cells: mining for novel therapeutic targets in the treatment of thyroid carcinoma. Curr Drug Targets Immune Endocr Metabol Disord 4: 187-198, 2004.

8 Willis SN and Adams JM: Life in the balance: how BH3-only proteins induce apoptosis. Curr Opin Cell Biol 17: 617-625, 2005.

9 Thompson CB: Apoptosis in the pathogenesis and treatment of disease. Science 267: 1456-1462, 1995.

10 Mitsiades N, Poulaki V, Mitsiades CS, Koutras DA and Chrousos GP: Apoptosis induced by FasL and TRAIL/Apo2L in the pathogenesis of thyroid diseases. Trends Endocrinol Metab 12: 384-390, 2001.

11 Andrikoula $\mathrm{M}$ and Tsatsoulis A: The role of Fas-mediated apoptosis in thyroid disease. Eur J Endocrinol 144: 561-568, 2001.

12 Mitsiades CS, Poulaki V and Mitsiades N: The role of apoptosisinducing receptors of the tumor necrosis factor family in thyroid cancer. J Endocrinol 178: 205-216, 2003.

13 Lin JD: The role of apoptosis in autoimmune thyroid disorders and thyroid cancer. BMJ 322: 1525-1527, 2001.

14 Temiz P, Akkaş G, Neşe N, Uğur Duman F, Karakaş C and Erhan Y: Determination-of apoptosis and cell cycle modulators (p16, p21, p27, p53, BCL-2, Bax, BCL-xL, and cyclin D1) in thyroid follicular carcinoma, follicular adenoma, and adenomatous nodules via a tissue microarray method. Turk $\mathbf{J}$ Med Sci 45: 865-871, 2015. 
15 Letsas KP, Frangou-Lazaridis M, Skyrlas A, Tsatsoulis A and Malamou-Mitsi V: Transcription factor-mediated proliferation and apoptosis in benign and malignant thyroid lesions. Pathol Int 55: 694-702, 2005.

16 Yang E, Zha J, Jockel J, Boise LH, Thompson CB and Korsmeyer SJ: Bad, a heterodimeric partner for Bcl-XL and Bcl2, displaces Bax and promotes cell death. Cell 80: 285-291, 1995.

17 Seo SY, Chen YB, Ivanovska I, Ranger AM, Hong SJ, Dawson VL, Korsmeyer SJ, Bellows DS, Fannjiang Y and Hardwick JM: $\mathrm{BAD}$ is a pro-survival factor prior to activation of its proapoptotic function. J Biol Chem 279: 42240-42249, 2004.

18 Mezosi E, Yamazaki H, Bretz JD, Wang SH, Arscott PL, Utsugi S, Gauger PG, Thompson NW and Baker JR Jr.: Aberrant apoptosis in thyroid epithelial cells from goiter nodules. J Clin Endocrinol Metab 87: 4264-4272, 2002.

19 Wattel S, Mircescu H, Venet D, Burniat A, Franc B, Frank S, Andry G, Van Sande J, Rocmans P, Dumont JE, Detours V and Maenhaut C: Gene expression in thyroid autonomous adenomas provides insight into their physiopathology. Oncogene 24: 69026916, 2005
$20 \mathrm{Ma}$ Y, Qin H and Cui Y: MiR-34a targets GAS1 to promote cell proliferation and inhibit apoptosis in papillary thyroid carcinoma via $\mathrm{PI} 3 \mathrm{~K} / \mathrm{Akt} / \mathrm{Bad}$ pathway. Biochem Biophys Res Commun 441: 958-963, 2013.

21 Ahmed M, Hussain AR, Bavi P, Ahmed SO, Al Sobhi SS, AlDayel F, Uddin S and Al-Kuraya KS: High prevalence of mTOR complex activity can be targeted using Torin2 in papillary thyroid carcinoma. Carcinogenesis 35: 1564-1572, 2014.

Received February 26, 2018

Revised March 14, 2018

Accepted March 19, 2018 